European Association for the

Development of Renewable Energies Environment and Power Quality (EA4EPQ)
International Conference on Renewable Energies and Power Quality (ICREPQ'11)

Las Palmas de Gran Canaria (Spain), 13th to 15th April, 2011

\title{
Study and Analysis of Voltage Dips in an Adjustable Speed Drives
}

\author{
C. Olarte ${ }^{1}$, J. González ${ }^{1}$, J. Pérez ${ }^{1}$
}

1 Department of Electrical Engineering - University of La Salle

Bloque C Piso 7, Carrera 2 No 10 - 70 Bogotá - Colombia.-e_mail: jjperez@unisalle.edu.co

\begin{abstract}
Currently, voltage dips are the most common disturbance of power quality. The voltage dips are a great problem on industrial process controlled by Adjustable Speed Drives (ASD). This paper describes an experimental study for evaluating the behavior of ASD when voltage dips appear. The measured parameters are: input and output voltage, input and output current, motor speed and torque. Finally this paper presents a development of a tolerance curve of ASD in order to study.
\end{abstract}

\section{Key words}

ASD, voltage, current, torque, motor speed, dips, tolerance curve.

\section{Introduction}

A voltage dip is defined by standard IEEE 1159-1995 [1], as a voltage reduction between 0.9 to 0.1 p.u., in root-mean-square, with a duration between 8.33 milli second until 1 minute.

Figure 1. Phasor diagram voltage dip type A.

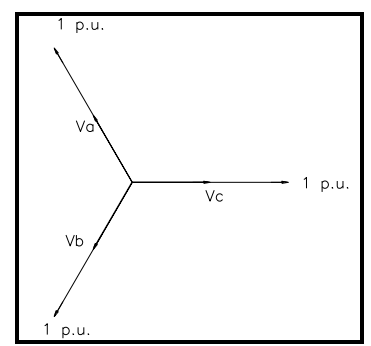

Figure 2. Waveform voltage dip type A.

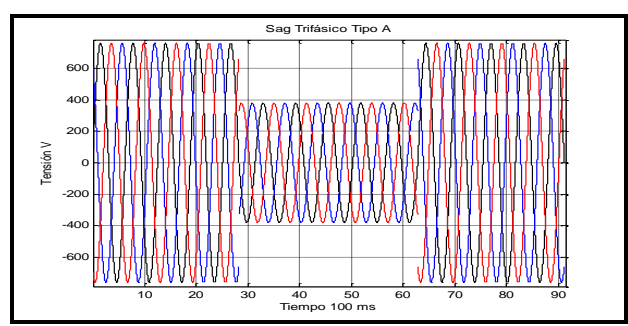

One of the voltage dips that causes a greatest impact on industrial processes is the voltage dip type A. This voltage dip is a reduction in the three phases of an electric system. At the same time these voltages dip are a consequence of a threephase fault in the power system [3].
The figure 1 shows of phasorial diagram of voltage dip type A, The figure 2 shows of a reduction in three phases in a waveform voltage.

Among the industrial process, the most vulnerable ones to voltage dips are the following:

- Food industry.

- Plastics industry.

- Beer industry.

- Paper industry.

- Ceramics industry.

- Petrochemical industry.

- Textil industry.

- Wooden industry.

- Metallugircal industry.

- Steel industry.

Table I. - Sensitive equipment to voltage dips [2]

\begin{tabular}{|c|c|c|}
\hline Equipment & Vmin(\%) & TMáx (ms) \\
\hline Starter motor & 50 & 40 \\
\hline PLC & $50-90$ & $8-20$ \\
\hline Adjustable speed drives inverters & 82 & 1.5 \\
\hline Adjustable speed drives rectifiers & $50-80$ & $2-3$ \\
\hline Process Controllers & 70 & $<8$ \\
\hline Computers & 70 & $<8$ \\
\hline Continous current controllers & 88 & $<8$ \\
\hline Contactors & $50-60$ & $20-30$ \\
\hline Electromagnetic switches & 50 & 10 \\
\hline $\begin{array}{c}\text { Electromagnetic relays and } \\
\text { starters }\end{array}$ & $50-60$ & $15-40$ \\
\hline $\begin{array}{c}\text { Sensitive load fed through } \\
\text { ferroresonant transformer }\end{array}$ & 50 & 500 \\
\hline
\end{tabular}

\section{Study methodology}

The methodology development test has the following stages:

A. Development of flow chart for testing. 
Figure 3. Flow chart of the implemented process by data acquisition.

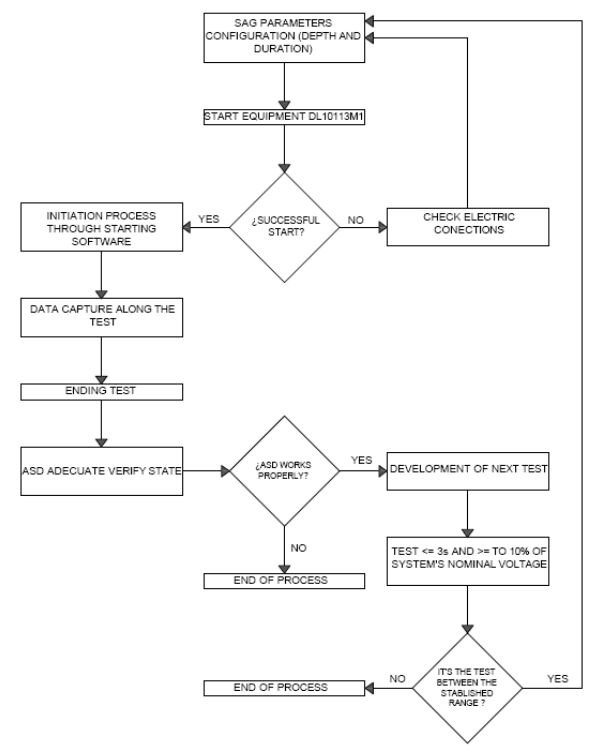

B. Labview code to implement flow chart.

Once the flow chart diagram is developed, is necessary to do some tests. These tests are programmed into Labview software. The figure 4 presents the code development [4].

Figure 4. Diagram programming interface.

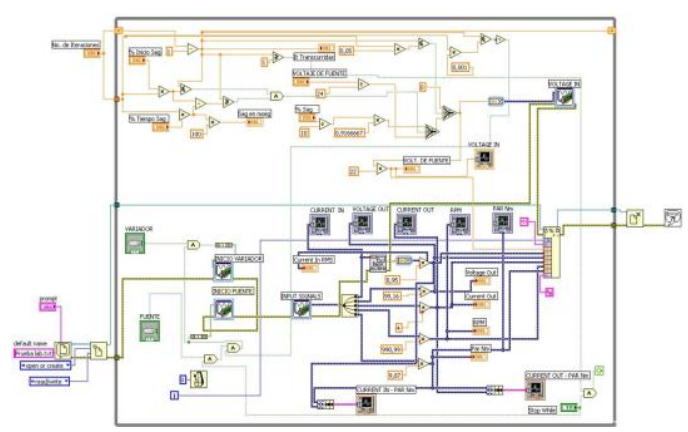

The figure 4 presents the algorithm developed through laboratory tests. The initial part calculates mathematically the start time, duration and magnitude of the voltage dip. After the calculation is over and the signals such as voltage input, voltage output, current input, current output, speed, and torque are acquired, all in relation to the ASD, the test is finished.

The figure 5 shows the control interface where user determinates the overall in which it will run the test. The interface presents: voltage dip start time, duration, magnitude and visualization of the others parameters such as torque, speed and current.

\section{Figure 5. Control interface}

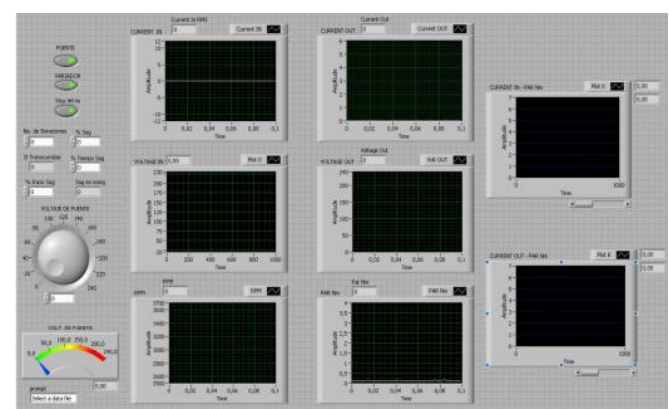

The control panel can be seen in the upper left control indicators such as: voltage source starting, iteration's number, depth of the voltage dip and duration's time of voltage dip. Moreover, interface can display the current input, current output, voltage input, voltage output, speed, torque and an additional graphic that shows the current output versus torque.

\section{Laboratory tests}

This part presents a development topology to laboratory test, which analyzes the behavior of ASD before different durations and magnitudes of voltage dips. Also it presents different measures before and after the ASD.

Figure 6. Diagram Connection for laboratory test.

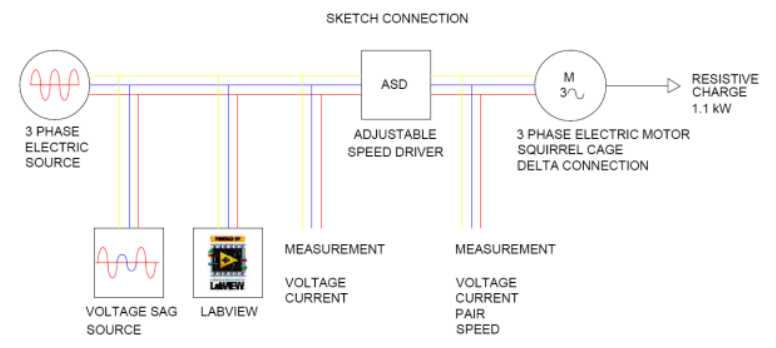

The table II shows electric features of motor under study.

Table II. - Features induction motor

\begin{tabular}{|c|c|c|c|c|c|c|}
\hline Phases & $\begin{array}{c}\text { Speed } \\
\text { (r.p.m) }\end{array}$ & & $\begin{array}{c}\text { Voltage } \\
\text { Nom. (V) }\end{array}$ & $\begin{array}{c}\text { Current } \\
\text { Nom (A) }\end{array}$ & IP & $\begin{array}{c}\text { Power } \\
\text { (kW) }\end{array}$ \\
\hline 3 & 3580 & Delta & 220 & 5 & 55 & 1100 \\
\hline 3 & 3580 & Wye & 220 & 3 & 55 & 1100 \\
\hline
\end{tabular}

Table III. - Electric features of frequency ASD Altivar 18.

\begin{tabular}{|c|c|c|c|}
\hline $\begin{array}{c}\text { Output direct } \\
\text { current }\end{array}$ & $\begin{array}{c}\text { Maximum } \\
\text { current (60s) }\end{array}$ & $\begin{array}{c}\text { Consumption } \\
\text { nominal } \\
\text { Power }\end{array}$ & Weight \\
\hline $\mathrm{A}$ & $\mathrm{A}$ & $\mathrm{W}$ & $\mathrm{kg}$ \\
\hline 22.00 & 33.00 & 200 & 7.8 \\
\hline
\end{tabular}

\section{Results}

The Voltage dips were applied through steps of $10 \%$ from $10 \%$ to $90 \%$, of r.m.s nominal value, and for times of 500 milliseconds, 1000 milliseconds and 1700 milliseconds. The results are summarized in the figure 7 to figure 11 .

\section{A. Graphics results}

Figure 7 shows the voltage behavior in each of the tests with different depths in nominal voltage, from $10 \%$ until $90 \%$ of value r.m.s.

Figure 8 shows the behavior of output voltage of the ASD. For the caused disturbance in the output voltage to 1000 milliseconds is similar in depth range from $60 \%$ to $10 \%$, where is obvious a decreased in speed. 
Figure 7. Input voltage for a duration of $500 \mathrm{~ms}, 1000 \mathrm{~ms}$ and $1700 \mathrm{~ms}$.

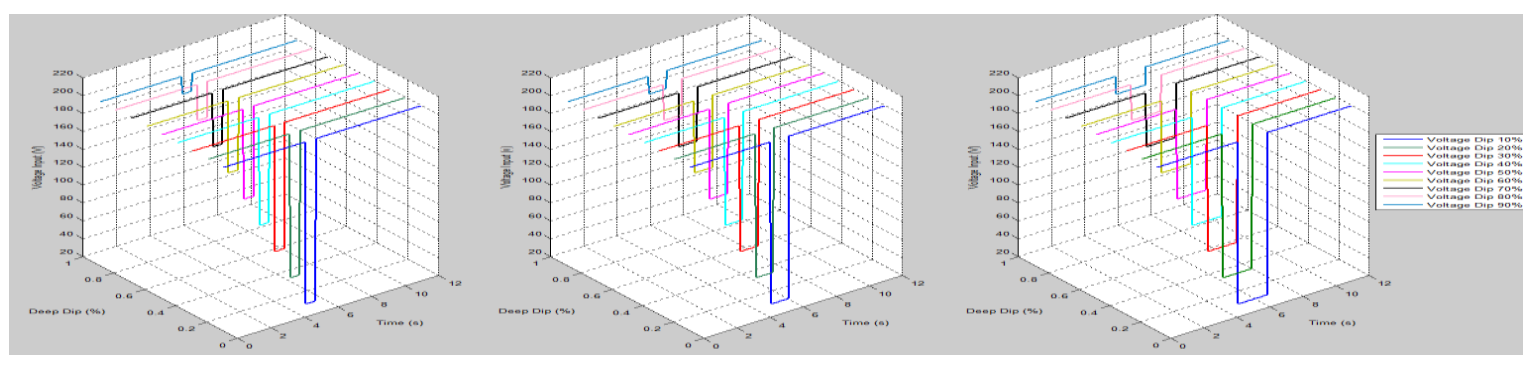

Figure 8. Output voltage for a duration of $500 \mathrm{~ms}, 1000 \mathrm{~ms}$ and $1700 \mathrm{~ms}$.

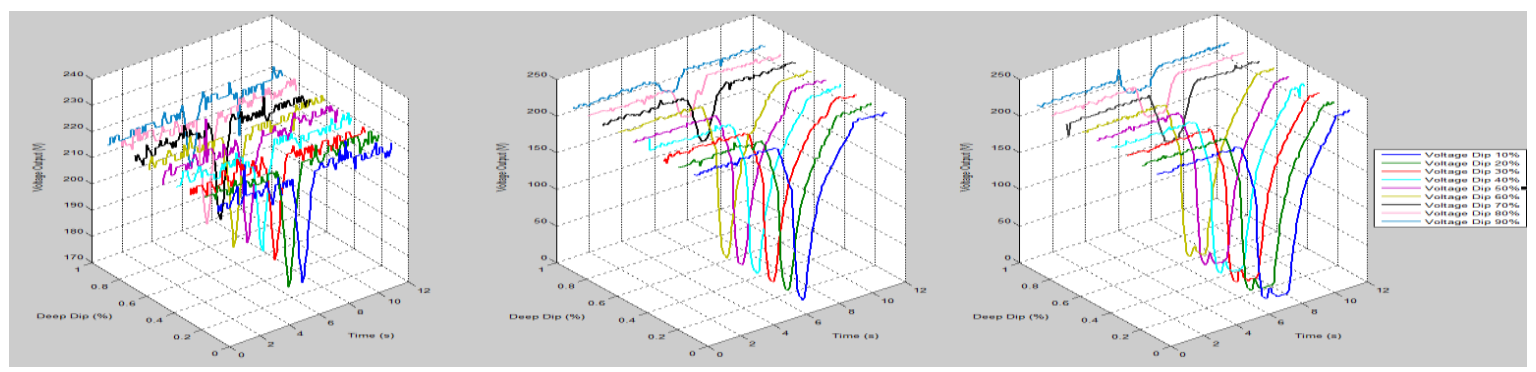

Figure 9. Output current for a duration of $500 \mathrm{~ms}, 1000 \mathrm{~ms}$ and $1700 \mathrm{~ms}$.

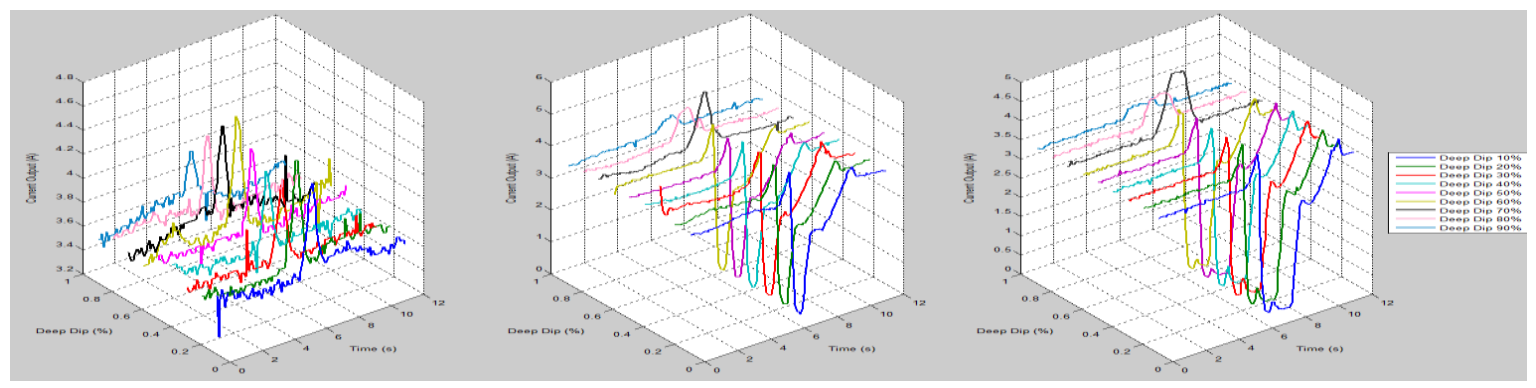

Figure 10. Speed for a duration of $500 \mathrm{~ms}, 1000 \mathrm{~ms}$ and $1700 \mathrm{~ms}$.

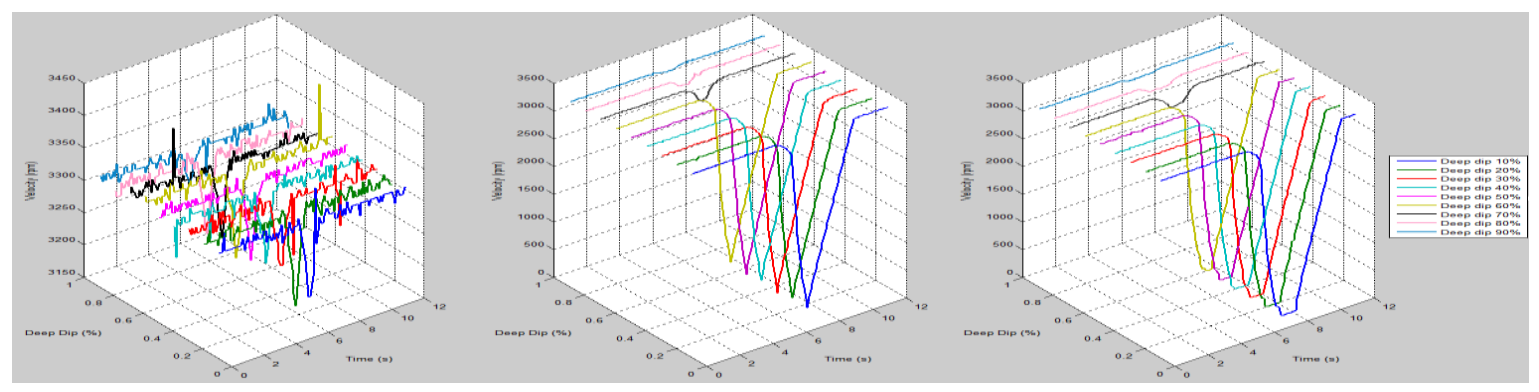

Figura 11. Torque for a duration of $500 \mathrm{~ms}, 1000 \mathrm{~ms}$ and $1700 \mathrm{~ms}$.

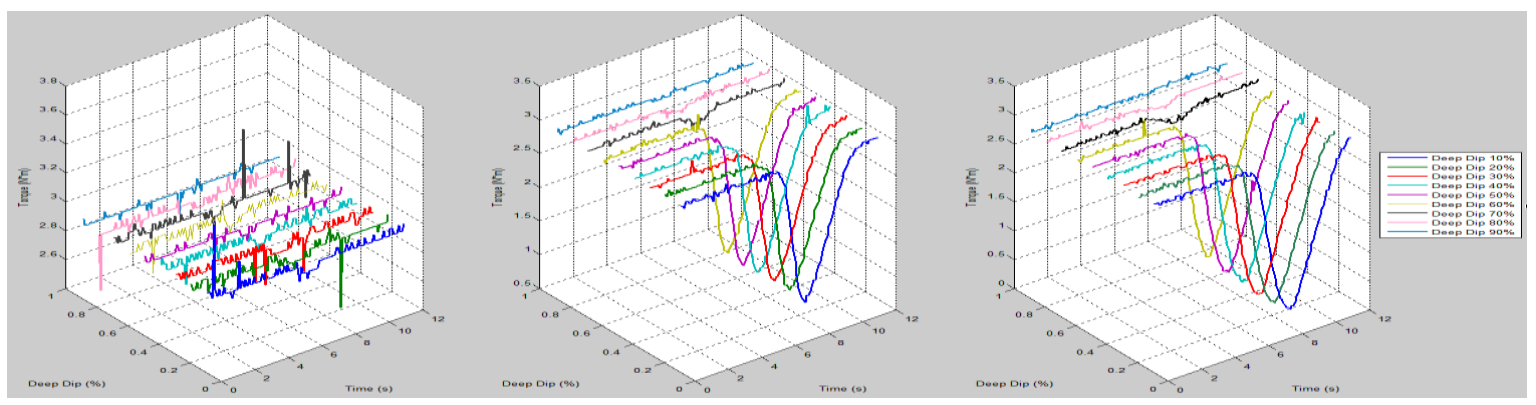


Figure 9 shows the current variations with increasing, proportional with the variation of duration and magnitude of voltage dip. For example, for dips with depths higher of 50\% and durations higher to 500 milliseconds, it exceeds the nominal current over $10 \%$.

Now, in the case of speed as shown figure 10, for voltage dips with a duration of 1000 milliseconds, the speed is reduced until 3150 r.p.m. with a voltage with 0.7 p.u. of nominal voltage, but when the duration is close to 1700 milliseconds, the speed is reduced to 0 r.p.m. It shows the severity for voltage dips higher than 1000 milliseconds.

The figure 11 shows the nominal value of torque, which is 2.9 $\mathrm{N}^{*} \mathrm{~m}$, but when occurs a voltage dip, with a duration 1000 milliseconds, with a depth of $70 \%$, torque is reduced to 0.5 $\mathrm{N}^{*} \mathrm{~m}$. For duration exceeding 1000 milliseconds torque is reduced near 0 r.p.m.

\section{B. Analysis through bars.}

The following is presented in detail the results as bars of tests for a duration of 500, 1000 and 1700 milliseconds respectively, for a dip type $\mathrm{A}$, in the parameter voltage.

Figura 12. Reduction of output voltage due dips.

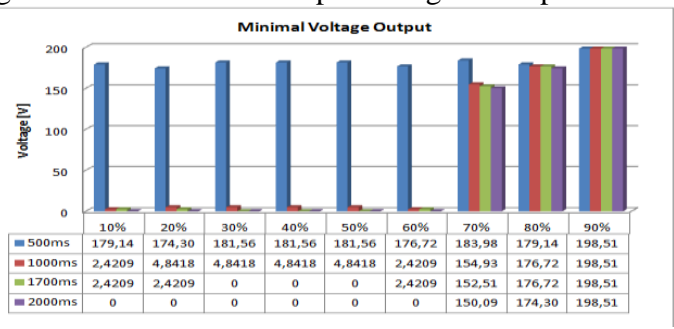

Figure 12 shows the voltage drops with depths $10 \%$ between $60 \%$ with durations about 1000, 1700 and 2000 milliseconds are reduced the voltage output to $0 \mathrm{~V}$, ASD, therefore acts undervoltage protection. The undervoltage threshold is reached at the test depth of $70 \%$ with duration of 1700 milliseconds, i.e. this critical value.

Figure 13. Current increase due dips.

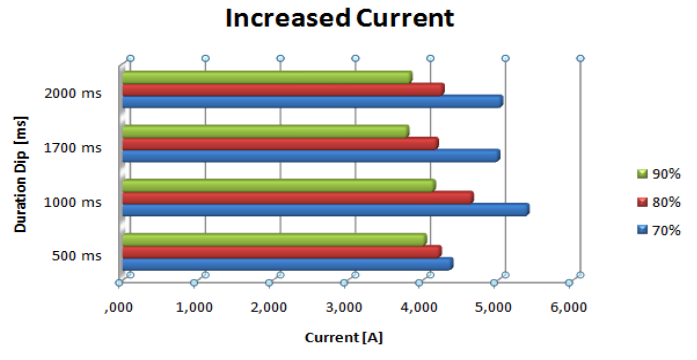

Now, figure 13 illustrates the different values of the depths and its duration, keeping in mind that the rated current is $3.8 \mathrm{~A}$, the increases are quite visible when apply voltage dip a $70 \%$ depth and duration of 1700 milliseconds, which reaches 5.39 A, value increased $50 \%$ above nominal.
Table IV. - Speed reduction.

\begin{tabular}{|c|c|c|c|c|c|}
\hline $\begin{array}{c}\text { Time / } \\
\text { Depth }\end{array}$ & $10 \%$ & $20 \%$ & $30 \%$ & $40 \%$ & $50 \%$ \\
\hline $500 \mathrm{~ms}$ & $96.8 \%$ & $95.9 \%$ & $97.4 \%$ & $97.1 \%$ & $96.8 \%$ \\
\hline $1000 \mathrm{~ms}$ & $5.30 \%$ & $5.90 \%$ & $3.50 \%$ & $5.90 \%$ & $4.10 \%$ \\
\hline $1700 \mathrm{~ms}$ & $0.00 \%$ & $0.00 \%$ & $0.00 \%$ & $0.00 \%$ & $0.00 \%$ \\
\hline $2000 \mathrm{~ms}$ & $0.00 \%$ & $0.00 \%$ & $0.00 \%$ & $0.00 \%$ & $0.00 \%$ \\
\hline
\end{tabular}

The table 4 presents a resume of results in speed. With voltage dips at depths between $10 \%$ to $60 \%$ speed reductions ranging between $10 \%$ to $50 \%$.

In other tests, with durations exceeding 1000 milliseconds and depths higher than $70 \%$, the speed is reduced to about 0 r.p.m.

\section{Tolerance curve}

The Cbema immunity curve was originally developed by Cbema [5] (Technology Industry Council), to describe tolerance of main frame computer equipment to the magnitude and duration of voltage variations in power systems in conditions of undervoltages and overvoltages.

In 1996 the Cbema curve was substituted by the Information Technology Industry Council (ITIC) curve [6]. This curve describes an A.C. input voltage envelope that can be typically tolerated by most IT equipment without any loss of function.

In the figure 15 presents the elaboration tolerance curve ASD under study, after different tests for determine the equipment function is acceptable or unacceptable. Shown in the figure three regions, the first region shown operate condition, the second region shown, current nominal above 1.15 times nominal current, and third region shown when the ASD is disconnect.

Figure 15. Tolerance curve ASD under study.

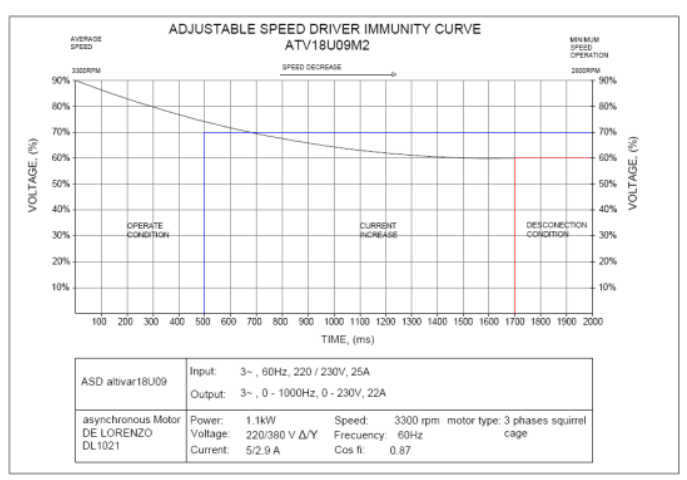

In the figure 15 , you can see when a voltage dip balanced of $60 \%$ of nominal voltage, with duration of $1700 \mathrm{~ms}$, disconnecting the motor, in this moment supply voltage not is enough to operate to ASD. In this case of nominal speed, decrease until 0 r.p.m.

\section{Discussion}

This papers shows different test applied to ASD under study, connected a electrical motor of $1.1 \mathrm{~kW}$. Tests were developed from 100 milliseconds until 2000 milliseconds, with depths from $10 \%$ until $90 \%$ of nominal voltage.

In the analysis performed for each parameter such as voltage, current, speed and torque. The ASD continues operating under 
dips about $500 \mathrm{~ms}$ and depths from 50\% until $90 \%$. The output current increases to $30 \%$ over the nominal current.

For the ASD controller under study, due to its topology, It compensates the reduction speed of motor when exists a voltage dip, but when is activated the undervoltage protection of the ASD is disconnected.

According to industrial process, can determine the sensitivity of reduction torque and speed, in this case study the equipment operates undervoltage protection, and then restart again when the voltage recovers. In many industrial processes production can be dangerous that events voltage dips.

Finally we obtained the tolerance curve of ASD under study, determining operation area, disconnecting area; it's important mentioned that every ASD have their own tolerance curve according his equipment, use conditions and industrial processes.

There are several equipments that may help mitigate the effect of sags such as DVR, STATCOM, FLYWHEL, UPS. It's necessary to conduct a detailed study of the load and the type of events to determine that equipment should be installed to avoid lost economic production.

\section{References}

[1] IEEE Std 1159- 1995. "Recommended Practice for Monitoring Electric Power Quality. Institute of Electrical and Electronics Engineers". 70 Pág. New York. 1995.

[2] ORDOÑEZ, G. "Perturbaciones en la onda de tensión huecos y sobretensiones", Cartagena de Indias. Febrero 2002.

[3] BOLLEN, M. "Understanding power quality problems: voltage sags and interruptions". IEEE Press. 2001. New York.

[4] PÉREZ, J. C, CORTÉS. GÓMEZ, A. "A study voltage sags in electric motors". $9^{\circ}$ International Conference, Electric Power Quality and Utilisation. October 9 - 11. Barcelona. España. 2007

[5] Cbema curve. Avalaible online on http://www.itic.org. published by Information Technology Industry Council. 1250 EyeStreet. NW Suite 200 Washington D.C.

[6] ITIC curve. Avalaible online on http://www.itic.org. published by Information Technology Industry Council. 1250 Eye Street. NW Suite 200 Washington D.C. 